\title{
OTOMYCOSIS: AN OVERVIEW IN HYDERABAD KARNATAKA REGION
}

\author{
R. B. Chapparbandi' ${ }^{1}$ Farha Naaz Kazi², Kazim Ali ${ }^{3}$
}

\section{HOW TO CITE THIS ARTICLE:}

R. B. Chapparbandi, Farha Naaz Kazi, Kazim Ali. "Otomycosis: An Overview in Hyderabad Karnataka Region". Journal of Evolution of Medical and Dental Sciences 2014; Vol. 3, Issue 46, September 22; Page: 11213-11216, DOI: $10.14260 /$ jemds/2014/3462

ABSTRACT: Otomycosis is a common clinical problem in Hyderabad Karnataka region because of the hot, humid climate of this region. The infection can be diagnosed clinically on the basis of symptoms like itching, otalgia, discharge, blockage, hearing loss and presence of debris resembling wet blotting paper appearance in the external auditory meatus. It is common in males and occurs more in the 2130 year age range. The most common symptoms in our review were itching followed by hearing loss, otorrhoea and blockage. Otomycosis was predominantly unilateral with left ear affected more. The species of fungus causing the disease in our center is Aspergillus Niger. Drugs like clotrimazole/ lidocaine, acetic acid hydrochloride (eardrops) or Gentian violet are indispensible topical agents in the management of otomycosis. Gentian violet should only be used as treatment of last resort because it discolors the external auditory canal giving a poor cosmetic appearance during treatment.

KEYWORDS: Otomycosis, clinical diagnosis, treatment.

INTRODUCTION: Otomycosis is generally described in literature as fungal infection of the external auditory canal. It can be associated with chronic middle ear discharge and open mastoid cavity infection. Hundred or more species of fungi are identified as pathogens till date. The common aetiological agents include the Aspergillus species; A fumigatus, A Niger and the Candida species; Candida albicans. Other fungi involved are, Penicillium, Pitirosporum.[1,2,3]

Otomycosis has a worldwide distribution with more prevalence in warm, wet, humid and dusty environments. Its incidence has increased due to increasing use of antibiotics, immune suppressant and bad aural hygiene, instilling hot oil and water in the ear. The disease is said to be commoner on those who wear head covers in some parts of the World. ${ }^{[5]}$ It is also common among swimmers hence sometimes called "swimmers ear".

Symptoms usually include: itching, otalgia, otorrhoea, ear blockage, hearing loss and tinnitus.[9,10,11] Examination usually reveals the presence of debris ranging in colour from white to black resembling "wet blotting paper" in the external auditory meatus. Diagnosis is usually clinical with mycologic studies to confirm the particular species of causative fungi. Treatment is by suction clearance or aural syringing followed by topical anti-fungal agents. Many antifungals were used for otomycosis with different percentage of success but standard regime is not firmly established.

PATIENTS AND METHODS: This retrospective study was carried out at the Otorhinolaryngology (ORL) department of our hospital. The study was carried out on 159 cases clinically diagnosed as mycotic otitis externa attending our outpatient department.

Clinic records of patients seen within this period with a history of ear complaints were reviewed for age, sex, clinical symptoms, laterality, and duration of symptoms, previous medications and treatment given. The diagnosis of otomycosis was based on clinical history and otoscopic examination. 
The clinical symptoms of itching, otalgia, ear blockage, hearing loss, and discharge in the ear canal were regarded as clinical diagnostic of otomycosis. After clinical diagnosis is made, all cases were subjected for mycological examination. Two sterile swabs were collected from ear canal of each patient. One swab was cultured on Saboraud's medium to which Chloromycetin and actidol were added to suppress the growth of bacteria.

The inoculated plates were cultured at 37 degree Centigrade. The other swab was used for direct mycological examination using $10 \% \mathrm{KOH}$. Treatment was by one of two methods; Patients with suspected perforation of the tympanic membrane had aural toileting or suction clearance followed by topical application of antifungal agents. Those with intact tympanic membranes had aural syringing followed by topical antifungal agents. Topical antifungal agents used were either; clotrimazole/ lidocaine hydrochloride-(Candid eardrops) or Gentian violet.

RESULTS: In the period under review, 159 patients were diagnosed as otomycosis in the outpatient clinic. Ear symptoms suggestive of otomycosis were; Pruritus (93\%), Otalgia (84\%), Musky ear discharge (73.5\%), Blockage (79\%), Hearing loss (50.3\%), and Tinnitus (39\%). Table II Of the 159 patients, unilateral left ear was affected in $80(50.32 \%)$, unilateral right ear was affected in $69(43.39 \%)$, and bilateral affected is 10 patients (6.29\%). Table III

Treatment was repeated in 35 patients who had recurrent infection. Of these, $27(77.1 \%)$ had cure while symptoms persisted in 8 (22.9\%). The patients were commonly affected by Aspergillus species. Aspergillus Niger (55.97\%), Aspergillus flavus (28.94\%), Aspergillus fumigates (4.41\%) followed by Candida species (1.25\%) Table IV.

\begin{tabular}{|c|c|c|}
\hline Age (in years) & No. of patients & Percentage \\
\hline $0-10$ & 25 & 15.72 \\
\hline $11-20$ & 42 & 26.42 \\
\hline $21-30$ & 45 & 28.30 \\
\hline $31-40$ & 19 & 11.95 \\
\hline $41-50$ & 13 & 8.18 \\
\hline $51-60$ & 09 & 5.66 \\
\hline $61-70$ & 04 & 2.52 \\
\hline $71-80$ & 02 & 1.25 \\
\hline Total & $\mathbf{1 5 9}$ & $\mathbf{1 0 0 . 0}$ \\
\hline
\end{tabular}

TABLE I: Age distribution of patients $(n=338)$

\begin{tabular}{|l|c|c|}
\hline \multicolumn{1}{|c|}{ Symptoms } & No. of cases & Percentage \\
\hline Itching in the ear & 149 & 93.37 \\
\hline Pain & 135 & 84.90 \\
\hline Feeling of block sensation & 126 & 79.25 \\
\hline Ear discharge & 117 & 73.59 \\
\hline Tinnitus & 63 & 39.62 \\
\hline Deafness & 55 & 34.60 \\
\hline Others & 2 & 1.25 \\
\hline
\end{tabular}

TABLE II: Common signs and symptoms of otomycosis 


\begin{tabular}{|l|c|c|}
\hline Laterality & No. of cases & Percentage \\
\hline Left & 80 & 50.32 \\
\hline Right & 69 & 43.39 \\
\hline Bilateral & 10 & 6.29 \\
\hline Total & $\mathbf{1 5 9}$ & $\mathbf{1 0 0}$ \\
\hline
\end{tabular}

TABLE III: Ear distribution of otomycosis

\begin{tabular}{|c|c|c|}
\hline Fungal isolate & No. of cases & Percentage \\
\hline Aspergillus niger & 89 & 55.97 \\
\hline Aspergillus flavus & 46 & 28.94 \\
\hline Aspergillus fumigates & 07 & 4.41 \\
\hline Candida albican & 11 & 6.93 \\
\hline Candida species & 02 & 1.25 \\
\hline Mucor species & 02 & 1.25 \\
\hline Penicillium & 02 & 1.25 \\
\hline Total & 159 & 100 \\
\hline
\end{tabular}

DISCUSSION: Otomycosis is a common clinical problem in our region. This is not surprising because of the hot humid, dusty climate of the region. $[1,4,5]$ According to Paulose et al otomycosis occurs more in those who wear head covers in certain parts of the world. ${ }^{5}$ Head covers increase moisture and heat and humidity around the ears.

Our diagnosis and treatment was presumptive based on clinical symptoms and signs including pruritus, otalgia, blockage hearing loss and presence of debris resembling wet newspaper in the external auditory meatus. This agree with literature reports that the infection can be diagnosed clinically on the basis of symptoms.[1,4,5]

Otomycosis was commoner in males as compared to study by M. M. Yehia et al who reported a higher incidence in females and mainly in housewives. ${ }^{[5]}$ In our study, the highest number of cases of otomycosis occurred in the 21-30 year age range similar to the findings of Ravinda Kaur et al in which otomycosis was more prevalent between the ages of 16-30 years.[1] These age groups do more swimming and physical exercises which predisposed them to otomycosis.

In our review, otomycosis was predominantly unilateral with left ear more affected. This agrees with many studies reporting that otomycosis is usually unilateral.[1,3,7] The most common symptoms in our review were pruritus followed by pain and blockage due to debris. Different studies have shown variations in the most common symptoms. Otalgia and blockage, ${ }^{[1,4]}$ discharge, ${ }^{[3]}$ itching, ${ }^{[5]}$ and otalgia. ${ }^{[8]}$

Our study highlights the most common fungi causing otomycosis. The species of fungus causing the disease in our setting is Aspergillus Niger. All the cases respond well to topical antifungal agents like clotrimazole. In conclusion, otomycosis is a common problem in Hyderabad Karnataka region and the most common etiological agent is Aspergillus Niger. 


\section{REFERENCES:}

1. Kaur R, Mittal N, Kakkar M, Kumar A. Arggawal Morheshwarr, Dayal Malhur. Otomycosis: A Clinicomycologic Study. Ear, Nose \& Throat Journal August 2000.

2. Pontes ZB, Silva AD, Lima Ede O, Guerra Mde H, Oliveira NM, Carvalho Mde F, Guerra FS Otomycosis; A retrospecttiv study, Brazilian Journal of Otolarygology 200975 (3) 367-370.

3. Mahmoudabadi AZ, Masoomi SA, Mohammadi H. Clinical and mycological studies of Otomycosis Pak J Med Sci 2010; 26(1): 187-190.

4. Tang HO, Seffaory T. Vrabec, Donald Yoo, Nauton J. Coker, Otomycosis-Clinical features and treatment implications. Otolaryngology Head and Neck Surgery (2006) (135) 787-791.

5. Paulose KO, Al Khalifa S, Shenoy P, Sharma RK. Mycotic infection of the ear (otomycosis): A prospective study. J Laryngol Otol 1989; 103: 30-5.

6. Yehia MM, Al-Habib HM, Shehab NM. (1990), "Otomycosis - A common problem in North Iraq", The Journal of Laryngology and Otology, 104: 387-389.

7. Mogadam A Y, Asadi M A, Dehghani R, Hooshyar H. The Prevalence of Otomycosis in Kasham Iran during 2001-2003 Jundishapur Journal of Microbiology (2009); 2(1): 18-21.

8. Yehia MM, al-Habib HM, Shehab NM. Otomycosis: A common problem in north Iraq. J Laryngol Otol 1990; 104: 387-9.

9. Lakshmipati G, Murti RB. Otomycosis. J Indian Med Assoc 1960; 34: 439-41.

10. Pahwa VK, Chamiyal PC, Suri PN. Mycological study in otomycosis. Indian J Med Res 1983; 77: 334-8.

11. Mugliston T, O'Donoghue G. Otomycosis--a continuing problem. J Laryngol Otol 1985; 99: 32733. \{full_citation\}.

\section{AUTHORS:}

1. R. B. Chapparbandi

2. Farha Naaz Kazi

3. Kazim Ali

\section{PARTICULARS OF CONTRIBUTORS:}

1. Professor and HOD, Department of ENT, M.R. Medical College, Gulbarga.

2. Post Graduate, Department of ENT, M.R. Medical College, Gulbarga.

3. Post Graduate, Department of ENT, M.R. Medical College, Gulbarga.

\section{NAME ADDRESS EMAIL ID OF THE} CORRESPONDING AUTHOR:

Dr. R. B. Chapparbandi,

Room No. 10,

Department of ENT,

Basaveshwar Hospital,

Sedam Road, Gulbarga.

Email: drrbchapparbandi@gmail.com

Date of Submission: 27/07/2014.

Date of Peer Review: 28/07/2014.

Date of Acceptance: 15/09/2014.

Date of Publishing: 20/09/2014. 